\title{
Ethical Guidelines for Publication in Clinical Hemorheology and Microcirculation*
}

The identification and prosecution of scientific misconduct in research and publishing is a problem and a priority for every Journal. Issues related to financial conflicts, "paper splitting", simultaneous submission to more than one journal, the assignment of authorship ranks, and, importantly, scientific fraud and plagiarism need to be fully addressed. Reviewers, editors and readers are the first victims of any misbehavior, and in most cases have few possibilities to detect, or correct, it.

The Editors of Clinical Hemorheology and Microcirculation (CHM) firmly believe that the identification, investigation and prosecution of scientific misconduct are moral requirements and a necessary commitment to readers. From this perspective, a new policy has been introduced by the Editorial Board of CHM, which we hope will help prevent such episodes.

Starting 2010, CHM requires that authors comply with the following rules and provide a formal statement of acceptance of this code of scientific conduct:

- Data, text, figures and tables submitted must be original and unpublished, and cannot have been reproduced from other authors' publications or submitted for publication elsewhere unless clearly stated and with permission of the copyright holder.

- All authors must have complete access to the original data and accept responsibility for their scientific integrity.

- The corresponding author acts on behalf of all other authors, and he/she takes full responsibility for the content of the manuscript, including all data and text.

- All individuals who have actively contributed to the planning of the study, to the collection, interpretation and analysis of the data and/or to the writing of the manuscript, and who therefore have a right to be acknowledged as authors, must have read and approved the final version of the manuscript, including the list and order of authors.

- All contributions must be recognized, either by authorship or, as appropriate, in the acknowledgment section of the paper. Upon submission of a manuscript, the corresponding author is responsible that all co-authors and acknowledged contributors have approved its content, the content any subsequent revision, and all correspondence accompanying the paper.

- Approval of relevant organizations, panels, and/or review committees must have been obtained, including an ethics board for animal and/or human studies when appropriate. Further, all animal

\footnotetext{
${ }^{*}$ The Members of the Editorial Board decided to write this article during the Meeting of the Board of Editors of this Journal on the occasion of the 15th Conference of the European Society for Clinical Hemorheology and Microcirculation in Pontresina, Switzerland. The text was prepared by Tommaso Gori, revised by the Editors-in-Chief Sandro Forconi and Friedrich Jung and approved by the Editorial Board.
} 
and human procedures must comply with the International Declaration of Helsinki and the national laws of the country in which the study was performed.

- All authors must declare all financial or personal conflict of interest, past or present, especially when it may be perceived to impact the collection, interpretation or presentation of the data. While it is fully acceptable that research may be financed by for-profit organizations, the Editors believe that the source of any funding needs to be declared and acknowledged in any publication.

Rules of ethical behavior shall also apply after publication:

- The author(s) will notify IOS Press and obtain copyright permission should he/she/they wish to re-use the work for other publications, including publications in languages other than English. If authors wish to re-use only part of work published in CHM (e.g., a table or figure), they may do so as long as the original publication is quoted.

- Since, upon printing, the copyright of all material submitted for publications becomes property of IOS Press, the publisher holds the right to edit, publish, reproduce and distribute, include in indexes or search databases or through any media all parts of the manuscript.

- The Editors of Clinical Hemorheology and Microcirculation must be informed immediately, at any time before or after publication, if any of the above statements are found to be, or to have become, untrue. The Editors hold all rights to investigate and correct every aspect of a publication when it is felt to be associated with any form of scientific misconduct, including the right to retract the paper when already published.

- The corresponding author acts on behalf of all co-authors, and he is responsible that all authors and contributors have understood and accepted each of the rules above.

To document the acceptance of these rules of conduct, the following sentence must be reported in the acknowledgment section of every article submitted for publication in Clinical Hemorheology and Microcirculation: "The authors comply with the Ethical Guidelines for Publication in Clinical Hemorheology and Microcirculation as published on the IOS Press website and in Volume 44, 2010, pp. 1-2 of this journal". 